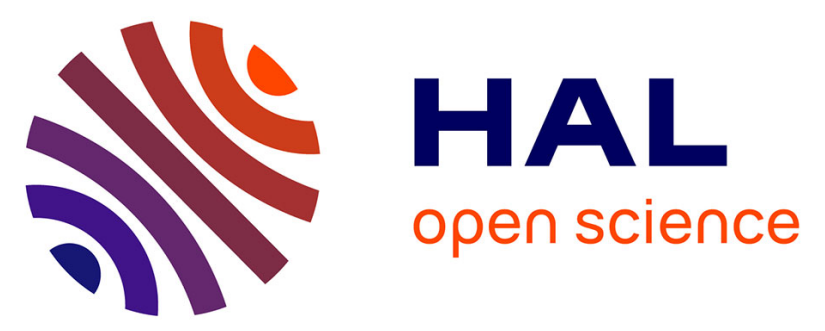

\title{
A Proposed Methodology for Subjective Evaluation of Video and Text Summarization
}

Begona Garcia-Zapirain, Cristian Castillo, Aritz Badiola, Sofia Zahia, Amaia

Mendez, David Langlois, Denis Jouvet, Juan-Manuel Torres-Moreno, Mikolaj

Leszczuk, Kamel Smaïli

\section{To cite this version:}

Begona Garcia-Zapirain, Cristian Castillo, Aritz Badiola, Sofia Zahia, Amaia Mendez, et al.. A Proposed Methodology for Subjective Evaluation of Video and Text Summarization. MISSI 2018 11th edition of the International Conference on Multimedia and Network Information Systems, Sep 2018, Wroclaw, Poland. pp.396-404, 10.1007/978-3-319-98678-4_40 . hal-01873685

\section{HAL Id: hal-01873685 \\ https://hal.science/hal-01873685}

Submitted on 19 Sep 2018

HAL is a multi-disciplinary open access archive for the deposit and dissemination of scientific research documents, whether they are published or not. The documents may come from teaching and research institutions in France or abroad, or from public or private research centers.
L'archive ouverte pluridisciplinaire HAL, est destinée au dépôt et à la diffusion de documents scientifiques de niveau recherche, publiés ou non, émanant des établissements d'enseignement et de recherche français ou étrangers, des laboratoires publics ou privés. 


\title{
A Proposed Methodology for Subjective Evaluation of Video and Text Summarization
}

\author{
Begona Garcia-Zapirain ${ }^{1}$, Cristian Castillo ${ }^{1}$, Aritz Badiola ${ }^{1}$, \\ Sofia Zahia ${ }^{1}$, Amaia Mendez ${ }^{1(凶)}$, David Langlois ${ }^{2}$, Denis Jouvet ${ }^{2}$, \\ Juan-Manuel Torres ${ }^{3}$, Mikołaj Leszczuk ${ }^{4}$, and Kamel Smaili ${ }^{2}$ \\ ${ }^{1}$ eVida Research Group, University of Deusto, Bilbao, Spain \\ amala.mendez@deusto.es \\ ${ }^{2}$ Loria, University of Lorraine, Lorraine, France \\ ${ }^{3}$ LIA, Universite d'Avignon et des Pays de Vaucluse, Avignon, France \\ 4 AGH University of Science and Technology Kraków, Kraków, Poland
}

\begin{abstract}
To evaluate a system that automatically summarizes video files (image and audio), it should be taken into account how the system works and which are the part of the process that should be evaluated, as two main topics to be evaluated can be differentiated: the video summary and the text summary. So, in the present article it is presented a complete way in order to evaluate this type of systems efficiently. With this objective, the authors have performed two types of evaluation: objective and subjective (the main focus of this paper). The objective evaluation is mainly done automatically, using established and proven metrics or frameworks, but it may need in some way the participation of humans, while the subjective evaluation is based directly on the opinion of people, who evaluate the system by answering a set of questions, which are then processed in order to obtain the targeted conclusions. The obtained general results from both evaluation systems will provide valuable information about the completeness and coherence, as well as the correctness of the generated summarizations from different points of view, as the lexical, semantical, etc. perspective. Apart from providing information about the state of the art, it will be presented an experimental proposal too, including the parameters of the experiment and the evaluation methods to be applied.
\end{abstract}

Keywords: Video summarization - Objective and subjective evaluation Text summary

\section{Introduction and Literature Review}

\subsection{Introduction}

AMIS is an original project concerning the second call: Human Language Understanding; Grounding Language Learning. This project acts on different data: video, audio and text. We consider the understanding process, to be the aptitude to capture the most important ideas contained in a media expressed in a foreign language, which would be compared to an equivalent document in the mother tongue of a user. In other words, the understanding will be approached by the global meaning of the content of a 
support and not by the meaning of each fragment of a video, audio or text. The idea of AMIS is to facilitate the comprehension of the huge amount of information available in TV shows, internet etc. One of the possibilities to reach this objective is to summarize the amount of information and then to translate it into the end-user language. Another objective of this project is to access to the underlying emotion or opinion contained in two medias. To do this, we propose to compare the opinion of two media supports, concerning the same topic, expressed in two different languages. The idea is to study the divergence and the convergence of opinions of two documents whatever their supports. Several skills are necessary to achieve this objective: video summarization, automatic speech recognition, machine translation, language modelling, sentimentanalysis, etc. Each of them, in our consortium, is treated by machine learning techniques; nevertheless human language processing is necessary for identifying the relevant opinions and for evaluating the quality of video, audio and text summarization by the end-user.

After analysing the existing different ways of evaluating an automatic summarizer system, and taking into account the objective of the actual evaluation, it is considered the best evaluation system a combination between subjective and objective evaluation methods. It is true that there are some automatic evaluation metrics/frameworks that have demonstrated good results, like ROUGE, QARLA... But these metrics/frameworks need human-generated summaries in order to compare, so, looking for the completeness of the evaluation, we consider necessary the inclusion of both perspectives of the analysis.

Besides, it should be considered that it is complicated to analyse automatic summaries with automatic systems using the lexical and phrase-based comparison with human generated summaries, obtaining really good proved results. Indeed, the humans, obviously, are not like machines; they have the ability to really understand, take the essence of something, and express it in a different way, in different words. So, it is possible to obtain a summary generated by a machine, and a summary generated by a human, and being in essence the same, but which can be expressed in a different way. In this case an automatic system probably will not be able to see the similarity in the words, the real meaning.

So, taking into account all the expressed ideas, the subjective evaluation is considered the best way to evaluate an automatic summarizer, and, to complete the evaluation from an objective perspective, it is interesting to apply some methods/metrics to analyze the obtained summaries. Anyway, both perspectives and their methods will be presented in the present document.

\subsection{Literature Review}

The state of the art of the evaluation of video summaries will be presented in the following tables from 2 perspectives: image and text. So, the most relevant and interesting papers about these topics are presented, including a resume about the most important part in relation with what we are analyzing, and some information about the parameters that are proposed (Table 1). 
Table 1. Video summary evaluation.

\begin{tabular}{|c|c|c|}
\hline Paper & Abstract & Experiment \\
\hline $\begin{array}{l}\text { Video Abstraction: A } \\
\text { Systematic Review and } \\
\text { Classification [1] }\end{array}$ & $\begin{array}{l}\text { Subjective: user studies } \\
\text { most useful and realistic }\end{array}$ & None \\
\hline $\begin{array}{l}\text { *VSUMM: A mechanism } \\
\text { designed to produce static } \\
\text { video summaries and a novel } \\
\text { evaluation method [2] }\end{array}$ & $\begin{array}{l}\text { Objective with user } \\
\text { participation: In this } \\
\text { evaluation method, called } \\
\text { Comparison of User } \\
\text { Summaries (CUS), the video } \\
\text { summary is built manually } \\
\text { by a number of users from } \\
\text { the sampled frames. The user } \\
\text { summaries are taken as a } \\
\text { reference to be compared } \\
\text { with the summaries obtained } \\
\text { by different methods. In this } \\
\text { way, the user summaries are } \\
\text { the reference summaries, i.e., } \\
\text { the ground-truth. Such } \\
\text { comparisons are based on } \\
\text { specific metrics, which are } \\
\text { introduced in the following } \\
\text { paragraphs }\end{array}$ & None \\
\hline $\begin{array}{l}\text { *A New Method for Static } \\
\text { Video Summarization Using } \\
\text { Local Descriptors and Video } \\
\text { Temporal Segmentation [3] }\end{array}$ & $\begin{array}{l}\text { Objective: } \boldsymbol{C U S} \text { makes a } \\
\text { comparison between the user } \\
\text { summary and the automatic } \\
\text { summary. The idea is to take } \\
\text { a keyframe from the user } \\
\text { summary and a keyframe } \\
\text { from the automatic video } \\
\text { summary }\end{array}$ & None \\
\hline $\begin{array}{l}\text { Automatic Evaluation } \\
\text { Method For Rushes } \\
\text { Summary Content [4] }\end{array}$ & $\begin{array}{l}\text { Subjective: Each submitted } \\
\text { summary was judged by } \\
\text { three different human judges } \\
\text { (assessors). An assessor was } \\
\text { given the summary and a } \\
\text { corresponding list of up } 12 \\
\text { topics from the ground truth }\end{array}$ & $\begin{array}{l}\text { - Users: } 3 \\
\text { - } 12 \text { topics selected from the } \\
\text { full video by the specialist }\end{array}$ \\
\hline
\end{tabular}


Table 1. (continued)

\begin{tabular}{|c|c|c|}
\hline Paper & Abstract & Experiment \\
\hline $\begin{array}{l}\text { Video Summarisation: A } \\
\text { Conceptual Framework and } \\
\text { Survey of the state of the art } \\
\text { [5] }\end{array}$ & $\begin{array}{l}\text { Objective methods do not } \\
\text { incorporate user judgment } \\
\text { into the evaluation criteria } \\
\text { but evaluate the performance } \\
\text { of a given technique based } \\
\text { on, for example, the extent to } \\
\text { which specific objects and } \\
\text { events are accurately } \\
\text { identified in the video stream } \\
\text { and included in the video } \\
\text { summary }\end{array}$ & $\begin{array}{l}\text { - Users: } 17 \\
\text { The users give feedback } \\
\text { about the content, in terms } \\
\text { of enjoyability and } \\
\text { informativeness by means of } \\
\text { informal discussions. }\end{array}$ \\
\hline $\begin{array}{l}\text { *A Pertinent Evaluation of } \\
\text { Automatic Video Summary } \\
\text { [6] }\end{array}$ & $\begin{array}{l}\text { Objective (similar to } \boldsymbol{C U S} \text { ): } \\
\text { They propose an effective } \\
\text { method for identifying the } \\
\text { true matches between AT } \\
\text { (Automatic Summary) and } \\
\text { GT (Ground Truth User } \\
\text { Summary) for the } \\
\text { performance evaluation of } \\
\text { the summarised videos. It } \\
\text { includes the initial } \\
\text { establishment of matched } \\
\text { frames via two-way search } \\
\text { followed by a consistency } \\
\text { check where weak and false } \\
\text { matches are eliminated }\end{array}$ & None \\
\hline $\begin{array}{l}\text { *Multi-video Summarization } \\
\text { Based On Video-MMR [7] }\end{array}$ & $\begin{array}{l}\text { - Objective (similar to } \\
\text { CUS ): Is meaningful to } \\
\text { compare Video-MMR } \\
\text { (Maximal Marginal } \\
\text { Relevance) to human } \\
\text { choice? In a video set, } 6 \\
\text { videos with most obvious } \\
\text { features were chosen. Inside } \\
6 \text { videos, } 3 \text { videos own the } \\
\text { largest distances with the } \\
\text { others in this video set, while } \\
\text { the other } 3 \text { videos have the } \\
\text { smallest distances }\end{array}$ & $\begin{array}{l}\text { - Users: } 12 \\
\text { - Full videos: } 3 \\
\text { Each user selects } 10 \\
\text { keyframes from each video }\end{array}$ \\
\hline
\end{tabular}


Table 1. (continued)

\begin{tabular}{|c|c|c|}
\hline Paper & Abstract & Experiment \\
\hline $\begin{array}{l}\text { *VERT: Automatic } \\
\text { Evaluation of Video } \\
\text { Summaries [8] }\end{array}$ & $\begin{array}{l}\text { By borrowing ideas from } \\
\text { ROUGE and BLEU, the } \\
\text { authors of this paper extend } \\
\text { these measures to the } \\
\text { domain of video } \\
\text { summarization. We focus } \\
\text { our approach on the } \\
\text { selection of relevant } \\
\text { keyframes, as a video skim } \\
\text { can be easily constructed by } \\
\text { concatenating video clips } \\
\text { extracted around the selected } \\
\text { keyframes... The authors } \\
\text { talk about VERT-Precision } \\
\text { and VERT-Recall, and how } \\
\text { they are carried out }\end{array}$ & None \\
\hline $\begin{array}{l}\text { VSCAN: An Enhanced } \\
\text { Video Summarization using } \\
\text { Density-based Spatial } \\
\text { Clustering [9] }\end{array}$ & $\begin{array}{l}\text { In this paper, a modified } \\
\text { version of an evaluation } \\
\text { method Comparison of User } \\
\text { Summaries (CUS) is used to } \\
\text { evaluate the quality of video } \\
\text { summaries. The } \\
\text { modifications proposed to } \\
\text { CUS method aims at } \\
\text { providing a more perceptual } \\
\text { assessment of the quality of } \\
\text { the automatic video } \\
\text { summaries }\end{array}$ & $\begin{array}{l}\text { CUS (but more complete i } \\
\text { our opinion) }\end{array}$ \\
\hline
\end{tabular}

\section{Experiment Design - Participants and Protocol for the Whole Integrated System}

Our proposed experiment includes two different lines: subjective evaluation (questionnaires) and objective evaluation.

In order to do the evaluation as complete as possible, and obtain the best results, the problem should be approached from different perspectives, so, it has been combined information from different sources $[13,14]$ and developed a new way of evaluation in order to obtain better results. On each perspective there are some questions with a specific format for the answer, which can be multiple choice or ranking from 0 to 4 formats. In the multiple choice format, some specific answers will be provided in order to be selected one or some of them by the user. In the case of the scoring from 0 to 4 , 
Table 2. Questionnaire for the video and text summary evaluation

\begin{tabular}{|c|c|c|c|c|c|c|}
\hline Criteria & 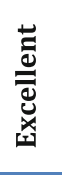 & 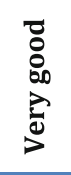 & ¿̊: & $\stackrel{\Xi}{\pi}$ & $\begin{array}{l}\stackrel{0}{0} \\
\stackrel{0}{0} \\
\ddot{0} \\
z\end{array}$ & 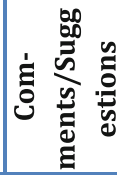 \\
\hline \multicolumn{7}{|c|}{ Summary video } \\
\hline $\begin{array}{l}\text { Is the summary under- } \\
\text { standable? }\end{array}$ & 4 & 3 & 2 & 1 & 0 & \\
\hline $\begin{array}{l}\text { The video doesn't con- } \\
\text { tain any part out of context, } \\
\text { or it does not affect to the } \\
\text { main expressed ideas }\end{array}$ & 4 & 3 & 2 & 1 & 0 & \\
\hline $\begin{array}{l}\text { Different questions about } \\
\text { the original video, in order } \\
\text { to ensure that the summary } \\
\text { contains the key ideas and } \\
\text { the user is able to get these } \\
\text { ideas from the summary }\end{array}$ & \multicolumn{6}{|c|}{ See below one example. } \\
\hline \multicolumn{7}{|c|}{ Summary text } \\
\hline $\begin{array}{l}\text { Is the summary under- } \\
\text { standable? }\end{array}$ & 4 & 3 & 2 & 1 & 0 & \\
\hline \begin{tabular}{lc}
\multicolumn{1}{l}{ Is $\quad$ it } & lexi- \\
cally/grammatically & cor- \\
rect? &
\end{tabular} & 4 & 3 & 2 & 1 & 0 & \\
\hline $\begin{array}{l}\text { Is it semantically cor- } \\
\text { rect? }\end{array}$ & 4 & 3 & 2 & 1 & 0 & \\
\hline $\begin{array}{l}\text { Does it contain redun- } \\
\text { dant information? }\end{array}$ & 4 & 3 & 2 & 1 & 0 & \\
\hline $\begin{array}{l}\text { Are the references (it, } \\
\text { she, he...) clear? (looking } \\
\text { for lack of information) }\end{array}$ & 4 & 3 & 2 & 1 & 0 & \\
\hline \multicolumn{7}{|l|}{$\begin{array}{l}\text { Different questions about } \\
\text { the original video, in order } \\
\text { to ensure that the summary } \\
\text { contains the key ideas and } \\
\text { the user is able to get these } \\
\text { ideas from the summary }\end{array}$} \\
\hline \multicolumn{7}{|c|}{ Summary video and summary text } \\
\hline $\begin{array}{l}\text { Do you think that both, } \\
\text { the summary video and the } \\
\text { summary text, express the } \\
\text { same idea? (cohesion be- } \\
\text { tween the both formats is } \\
\text { measured) }\end{array}$ & 4 & 3 & 2 & 1 & 0 & \\
\hline
\end{tabular}


each number has a meaning: $0=$ not done, $1=$ fair, $2=$ good, $3=$ very good and 4 = excellent. The subjective evaluation can be done in 2 ways:

\section{(a) Assessment of Summarized Video (image sequence) and Text}

Participants: 25 per language (Arabic and French) (balanced number of men and women)

Inclusion criteria: men and women over 18 years old, with at least high school level.

Exclusion criteria: reading and writing impairment. Understanding problems.

Number of summarized video and text per user: Every user will review a set of 3 videos (out of the 25 prepared) with mixed topics. The test will be made of the summarized video and text version (in English) (Table 2).

(b) Assessment of the Coherence between Original and Summarized Video and Text

Participants: Four in Arabic and four in French (two men and two women for each language)

Inclusion criteria: men and women over 18 years old, with at least high school level. The participants have to be fluent in both languages.

Exclusion criteria: reading and writing impairment. Understanding problems.

Number of summarized video and text per user: one with mixed topics. One video will be selected per language for the test with original (Arabic or French) and summarized video and text version (English) (Table 3).

Table 3. Questionnaire for original and summarized video and text evaluation

\begin{tabular}{|c|c|c|c|c|c|c|}
\hline Criteria & 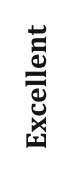 & $\begin{array}{l}\text { D } \\
0 \\
0 \\
0 \\
0 \\
0 \\
0\end{array}$ & J & 䒕 & 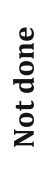 & 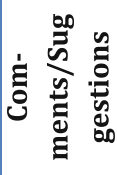 \\
\hline \multicolumn{7}{|c|}{ Original and summarized video and text } \\
\hline $\begin{array}{l}\text { Do you think that the } \\
\text { provided summarizations, } \\
\text { in video and in text, really } \\
\text { express the main ideas of } \\
\text { the original video? }\end{array}$ & 4 & 3 & 2 & 1 & 0 & \\
\hline $\begin{array}{l}\text { Can they be considered } \\
\text { good summaries? } \\
-\quad \text { Video } \\
-\quad \text { Text }\end{array}$ & 4 & 3 & 2 & 1 & 0 & \\
\hline $\begin{array}{l}\text { Are they long enough to } \\
\text { contain the main ideas? } \\
-\quad \text { Video } \\
-\quad \text { Text }\end{array}$ & 4 & 3 & 2 & 1 & 0 & \\
\hline $\begin{array}{l}\text { Do you consider it too } \\
\text { long? }\end{array}$ & 4 & 3 & 2 & 1 & 0 & \\
\hline
\end{tabular}


Below, we propose some examples of evaluation with original videos. Specific questions are asked for each video:

\begin{tabular}{|c|c|}
\hline $\begin{array}{l}\text { The-rise-of-chemsex-on-Londons- } \\
\text { gay-scene---BBC-News }\end{array}$ & Criteria \\
\hline $\begin{array}{l}\text { Which one is the main topic of the } \\
\text { summary? }\end{array}$ & $\begin{array}{l}\text { 1) Homosexual parties } \\
\text { 2) Homosexuality and STDs } \\
\text { 3) Homosexuality, drugs and STDs }\end{array}$ \\
\hline $\begin{array}{l}\text { The summary says that there is not } \\
\text { any relation between drugs and STD: }\end{array}$ & $\begin{array}{l}\text { 1) True } \\
\text { 2) False }\end{array}$ \\
\hline $\begin{array}{l}\text { The diagnosis of HIV with drugs is } \\
\text { related? }\end{array}$ & $\begin{array}{ll}\text { 1) } & \text { True } \\
\text { 2) } & \text { False }\end{array}$ \\
\hline
\end{tabular}

The assessment data analysis will consist on statistical analysis of questionnaires and the application of some machine learning techniques if possible for clusterization and comparison purposes between genders, language.

\section{Results}

The results regarding the questionnaires would be based in a point system, and the criteria of quality, or the different point ranges of quality level will be established depending on the total number of questions.

During 2018, all the proposed test will be carried out.

Acknowledgements. Research work funded by the Spanish Ministry of Economy, Competitiveness and Industry (Spain) conferred under the Chist-Era AMIS project.

\section{References}

1. Truong, B.T., Venkatesh, S.: Video Abstraction: A Systematic Review and Classification (2007)

2. Fontes de Avila, S.E., Brandão Lopes, A., da Luz Jr, A., de Alburquerque Araújo, A.: VSUMM: a mechanism designed to produce static video summaries and a novel evaluation method (2010)

3. Cayllahua Cahuina, E.J., Camara Chavez, G.: A New Method for Static Video Summarization Using Local Descriptors and Video Temporal Segmentation (2013)

4. Dumont, E., Bernard, M.: Automatic Evaluation Method for Rushes Summary Content (2009)

5. Money, A.G., Agius, H.: Video Summarisation: A Conceptual Framework and Survey of the State of the Art (2008) 
6. Kannappan, S., Liu, Y., Tiddeman, B.: A Pertinent Evaluation of Automatic Video Summary (2016)

7. Li, Y., Merialdo, B.: Multi-video Summarization Based on Video-MMR (2010)

8. Li, Y., Merialdo, B.: VERT: Automatic Evaluation of Video Summaries (2010)

9. Mohamed, K.M., Ismail, M.A., Ghanem, N.M.: VSCAN: An Enhanced Video Summarization using Density-based Spatial Clustering (2014)

10. Molina, A., Torres-Moreno, J.-M.: The Turing Test for Automatic Text Summarization Evaluation (2016)

11. Molina Villegas, A., Torres-Moreno, J.-M., Sanjuan, E.: A Turing Test to Evaluate a Complex Summarization Task (2013)

12. Lin, C.-Y., Hovy, E.: Manual and Automatic Evaluation of Summaries (2002)

13. Hassel, M.: Evaluation of Automatic Text Summarization: a practical implementation (2004)

14. Saziyabegum, S., Sajja, P.S.: Review on Text Summarization Evaluation Method (2017) 